\title{
Impact of manipulations of myogenesis in utero on the performance of adult skeletal muscle*
}

\author{
Charlotte A. Maltin ${ }^{1}$, Margaret I. Delday ${ }^{1}$, Kevin D. Sinclair ${ }^{2}$, \\ John Steven ${ }^{1}$ and Alan A. Sneddon ${ }^{1}$ \\ ${ }^{1}$ Rowett Research Institute, Greenburn Road, Bucksburn, Aberdeen, AB21 9SB, UK; and \\ ${ }^{2}$ Scottish Agricultural College, Craibstone Estate, Bucksburn, Aberdeen, AB21 9YA, UK
}

\begin{abstract}
The possibility that early fetal programming affects health or disease status in adult life has been considered in relation to tissues such as the cardiovascular system but not with respect to skeletal muscle. Since muscle mass and function are important for life, it is pertinent to ask whether events during the development of muscle in utero can affect the performance of the tissue in later life. This review discusses the factors that influence muscle performance, outlines the current understanding of myogenesis and examines how manipulations alter myogenic outcome after birth. The performance of muscle is determined by the number, type and size of the muscle fibres, these in turn being affected by a number of factors, and the evidence indicates that the proportions of types of muscle fibre have a heritable component. The formation of muscle occurs early in embryogenesis and it appears that the major impacts on myogenesis are associated with extremes of treatment or embryo manipulations. The impact of extremes of treatment or embryo manipulations on myogenesis is seen in the secondary fibres whereas primary fibres appear to be insensitive or protected. Overall, the opportunities for manipulation of myogenesis in utero to improve adult performance are limited.
\end{abstract}

There is a growing interest in the way in which fetal programming can influence the performance of an adult in later life. Attention has been focussed on tissues relevant to major diseases such as the cardiovascular system (Barker, 1996), but skeletal muscle, one of the major components of the body, has been largely ignored. The aims of this review are to outline the main performance parameters in adult muscle, to provide a general overview of muscle development and then to consider whether myogenic programming may be influenced in utero and, if so, how changes in myogenesis might affect adult performance.

\section{Factors that determine muscle performance in adults}

Skeletal muscle represents about $40 \%$ of body mass and is used not only for locomotion but also acts as a reservoir of amino acids that can be called upon in times of physiological stress or disease. Skeletal muscle as meat in livestock species also serves as an important source of dietary protein and micronutrients. The functional units of differentiated muscle are the muscle fibres, which are long, cylindrical multinucleated cells. The performance of muscle is related

Email: c.maltin@rri.sari.ac.uk

*This article is based on a presentation given at the British Society of Animal Science symposium 'Early Regulation of Mammalian Development' held in Aberdeen in September 2000. to its mass and its functional capacity in terms of its ability to generate strength, speed and duration of movement.

\section{Muscle mass and strength}

Muscle mass depends on the number and size of the muscle fibres. In general, the number of muscle fibres is set at birth (Rowe and Goldspink, 1969) and hyperplasia does not occur to any significant extent during postnatal mammalian growth, and some studies indicate that this may be true for avian and fish species (Battram and Johnston, 1991; Remignon et al., 1995). Consequently, any postnatal muscle growth in mammals relies largely on protein accretion leading to muscle fibre hypertrophy. Protein accretion depends on the balance between protein synthesis and protein degradation, with accretion rates highest in young growing animals and declining with age. The mechanism of both protein synthesis and degradation has been widely discussed and the factors that influence muscle protein accretion, for example, nutrition, insulin, innervation and growth factors are well recognized (for review, see Grizard et al., 1999).

Muscle mass contributes to body shape and the conformation of a carcase is important in terms of the quality and value of meat animals. Generations of selective breeding for meat production have resulted in highly muscled, lean animals, although the genetic mechanism that underpins this remains to be fully elucidated. The size of a muscle is 


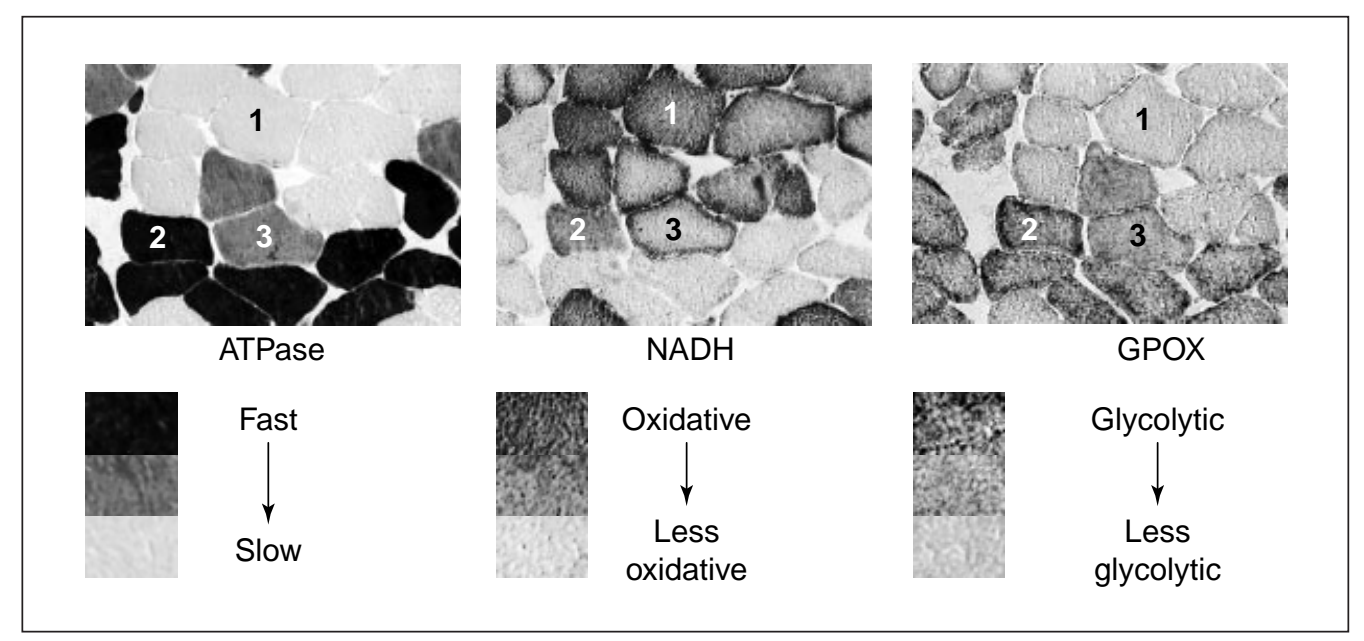

Fig. 1. A simple muscle fibre-type classification based on the density of the reaction product generated by the use of three staining reactions on transverse sections of muscle is shown. Formalin-insensitive $\mathrm{Ca}^{2+}$ activated ATPase activity (ATPase) at pH 9.4 was used to indicate contractile speed, nicotinamide adenine dinulceotide (NADH) was used to demonstrate mitochondrial activity and $\alpha$-glycerophosphate dehydrogenase (GPOX) indicated glycolytic activity. The density of the reaction product is graded, allowing the fibres to be classified according to the reaction intensity. Thus, slow-twitch oxidative (SO) fibres (1) have little reaction product for ATPase, consistent with their slow speed of contraction, but show a dense product for $\mathrm{NADH}$, highlighting their oxidative metabolism. In contrast, fast-twitch oxidative glycolytic (FOG) fibres (2) have a fast contractile speed and both aerobic and anaerobic metabolism, and therefore have a positive reaction for all three staining regimens. Fast-twitch glycolytic (FG) fibres (3) have a high speed of contraction owing to their anaerobic metabolism, and therefore have positive staining for both ATPase and GPOX but less reaction product for NADH.

important in relation to its strength and there is a close relationship between the cross-sectional area of a muscle and its ability to generate force (Fenn and Marsh, 1935). The importance of muscle strength has been highlighted by the finding that mid-life grip strength is a good predictor of long term mortality, independent of body mass index (Rantanen et al., 2000). The authors interpreted these results as indicating that early life influences on muscle strength may have long-term implications for mortality. Thus, factors that impinge on myogenic processes in utero to increase muscle cross-sectional area (for example, increases in the number or size of fibres) and ultimately lead to increased strength in the adult, may have benefits for survival.

\section{Muscle fibre type proportions}

Muscle fibres vary considerably in their morphological, biochemical and physiological properties. These properties are used to classify the fibres into at least two main fibre types: type I or slow-twitch oxidative (SO) fibres used for maintenance of posture or for endurance exercise; and type II or fast-twitch fibres used for more rapid bursts of activity. The fast-twitch fibres are divided into at least two classes: fast-twitch glycolytic (FG) and fast-twitch oxidative glycolytic (FOG), on the basis of their contractile and metabolic activities (Fig. 1).

The individual muscles in mature limbs contain a mixture of the different fibre types; very few muscles comprise solely one type. Therefore, muscles generically described as slow-twitch muscles, such as soleus, actually contain a proportion of fast-twitch fibres. As well as variations among muscles within an individual, there is also considerable variation among individuals and among breeds (Fig. 2). This variation in the proportions of fibre type may be one of the factors that determine the performance of the muscle in the adult, either in terms of athletic performance in humans (Gollnick et al., 1972) or of meat production in livestock. Evidence from pigs and cattle indicate that muscle fibre type proportions may influence the eating quality of meat (Karlsson et al., 1993; Koch et al., 1995; Zamora et al., 1996; Maltin et al., 1997, 1998a,b; Vestergaard et al., 2000) but the precise relationships between fibre type and sensory evaluation are not clear. Several studies have shown a positive relationship between SO fibre frequency and either tenderness or juiciness (for example, see Valin et al., 1982; Ockerman et al., 1984; Maltin et al., 1998b), whereas other data link the proportion of fast-twitch fibres with tenderness (Koch et al., 1995). In contrast, fast-twitch glyoclytic fibres may be associated with toughness. Muscles from callipyge lambs tend to be tougher than those from normal lambs (Duckett et al 2000) and show an increased frequency of fast-twitch glycolytic fibres and a lower proportion of fast-twitch oxidative glycolytic fibres (Carpenter et al., 1996). Although it is clear that fibre 
type proportions play some role in determining meat eating quality, further work is necessary to evaluate the precise relationship between this characteristic of living muscle and its quality as meat.

\section{Maturation and ageing}

In addition to the variation among individuals, the types and sizes of fibre in muscle change with age (Caccia et al., 1979; Eddinger et al., 1985; Monemi et al., 1998; Hughes and Schiaffino, 1999). As a muscle matures, the fibres hypertrophy and muscle mass increases. At the same time, there is a tendency for the functional area of slow fibres to increase with age (Fig. 3) (Caccia et al., 1979; Eddinger et al., 1985), consistent with the observed increase in relative endurance (Aoyagi and Shephard, 1992). In humans, there is a decline in muscle mass and force generation from about the age of 50 or 60 (Aoyagi and Shephard, 1992; Harris, 1997) as a result of a reduction in the number of muscle fibres (Aoyagi and Shephard, 1992) and a reduction in the synthetic rates of specific muscle proteins (Proctor et al., 1998). Similar changes are observed in other species. There are ethnic differences in the rate of muscle loss with ageing, with the rate lower in black women than in white women (Aloia et al., 2000). It is unclear whether this finding is the result of ethnic differences in the genetic regulation of initial muscle mass through the number or size of muscle fibres or in the control of muscle loss.

\section{Training}

The proportions of the different types of fibre in a muscle not only change with age but also show a considerable degree of plasticity in response to stimuli such as training (Gollnick et al., 1972; Abernethy et al., 1990). Indeed, the adaptations of muscle to the stresses of physical exercise underpin the current wealth of different training regimens used to maximize the athletic performance of muscle in animals and humans. Different types of training appear to lead to different adaptations with respect to both myosin heavy chain (MHC) isoform expression and metabolism within the muscle, such that the muscles of sprint- and endurance-trained athletes are reported to have different fibre-type characteristics (Costill et al., 1976). Sprint training tends to decrease the proportion of $\mathrm{SO}$ fibres and increase the proportion of FOG fibres. In contrast, endurance training tends to convert FG fibres to FOG fibres and to enhance the proportion of SO fibres. These effects of training illustrate the capacity of differentiated muscle to undergo fibre type transformations. There is evidence that these transformations are triggered by subtle changes in innervation. The mechanisms by which the neuronal firing patterns respond to training and the neuronal signals lead to changes in muscle gene expression are not fully understood, although a calcium-dependent, calcineurin signalling pathway has been implicated (Olson and Williams, 2000).

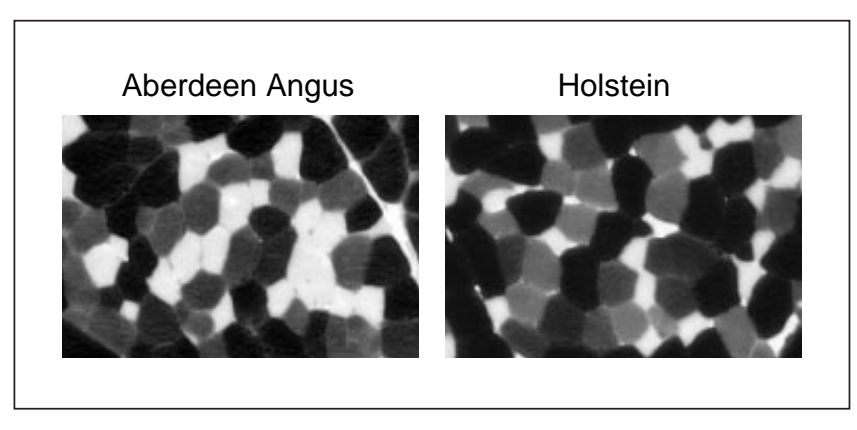

Fig. 2. Differences in muscle fibre-type proportions and fibre size between Aberdeen Angus and Holstein breeds of cattle. Transverse sections through the $m$ longissimus lumborum of different breeds of cattle of the same gender and age on the same feeding regimen reacted to demonstrate ATPase activity and show the variation in fibre-type proportions. Comparison between these two examples demonstrates the differences in fibre type and size between genotypes. Scale bar represents $100 \mu \mathrm{m}$.

\section{Inheritance}

The concept of heritable differences in muscle fibre characteristics is not new (Joubert, 1956; Saltin, 1973). Since there are incentives to select and train individual humans or other animals with the optimum physical characteristics to excel in a specific athletic event, there is considerable interest in the potential heritability of performance parameters and fibre composition. Evidence from both humans and racehorses indicates that fibre characteristics, particularly those relating to SO fibre types and endurance exercise, are heritable. Estimates of heritablility in humans range from $99.5 \%$ in one small study on twins (Komi et al., 1977) to approximately $30 \%$ in athletes (Thibault et al., 1986). Larger population studies from North America indicate that about $45 \%$ of the phenotypic variance in SO fibre proportions is associated with inherited factors (Simoneau and Bouchard, 1995).

Heritability in racehorses is similar to that reported for humans and is approximately 35\% (More O'Ferrall and Cunningham, 1974). The different proportions of SO fibres in the various equine breeds have been related to their selection over time for divergent performance characteristics (Snow, 1983). Consequently, heavy Hunters selected for endurance have a high proportion of SO fibres (31\%), whereas Thoroughbreds bred for sprint speed have a low proportion of SO fibres (13\%). These types of data do not come from strict experimental breeding protocols and it could be argued that adaptive factors such as training had played some role in the aetiology of these differences. However, in studies in inbred strains of mice, the heritability of the proportions of types of muscle fibre, the total number of fibres and the relative size of slow and fast fibres was highly significant (Nimmo et al., 1985). Indeed, the data showed that $57 \%$ of the variation in muscle composition could be accounted for by a genetic component. In livestock, it has been suggested that heritable differences in muscle fibre 

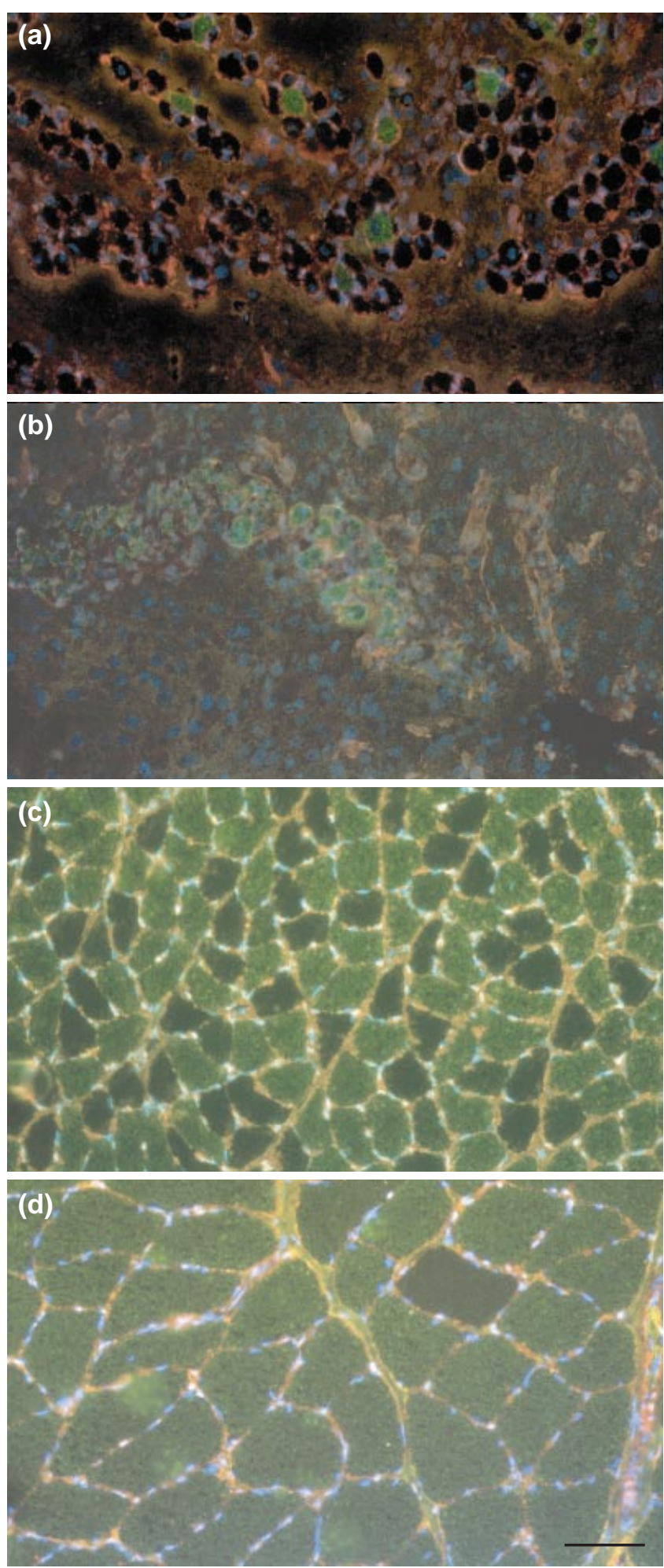

Fig. 3. The functional area of muscle fibres expressing slow myosin heavy chain $(\mathrm{MHC})$ isoform increases with age. Transverse sections of muscle samples labelled immunocytochemically to show the localization of slow MHC isoform (green) and laminin (red) and nuclei (blue). The samples illustrate the increase in slow fibre functional area with age in rats from the fetus to the mature adult. Slow myosin immunoreactivity is shown in: (a) the dorsal muscle characteristics explain part of the variation in eating quality. For example, Duroc pigs, known for producing meat of high eating quality have a higher proportion of SO fibres in their muscles than do Large White pigs, which produce meat of lower eating quality. Fibre-type analysis of pure- and crossbred animals showed that the SO fibre characteristics of Duroc animals are heritable and indicate that a single gene or gene cluster is responsible (Maltin et al., 1998a). Similarly, it has been suggested that the observed variation in eating quality between Aberdeen Angus and Holstein cattle may relate to genotypic differences in $\mathrm{SO}$ fibre proportions and metabolic characteristics (Lobley et al., 2000; Maltin et al., 2001). Although such a difference between cattle bred for meat and milk production, respectively, may not be so surprising, it does perhaps indicate that selection for product diversity has also selected for divergence in muscle metabolic and contractile properties.

If the heritability of the proportions of muscle fibre types is high, then this is not merely relevant to the selection and training of elite athletes, it may be important in relation to the predisposition of an individual to disease conditions. For example, the suggestion that SO fibre frequency is inversely related to fatness and that at least $40 \%$ of the variability in fatness is explained by variation in muscle fibre type (Wade et al., 1990) raises some interesting questions as to the aetiology and heritability of obesity. In addition, back pain with concomitant loss of muscle strength (Hultman et al., 1993) and endurance (Roy et al., 1990) has been shown to be associated with a significantly higher frequency and percentage area of FG fibres in the paraspinal muscles of patients with low back pain than in those of controls (Mannion et al., 1997). Although this finding may explain the symptoms of low back pain, it is also possible that the heritability of fibre characteristics may increase susceptibility to the condition.

The performance of muscle in adult animals appears to depend on the number, type and size of the fibres that comprise that muscle. The evidence indicates that, although muscle responds to stimuli such as training, a considerable part of the inter-individual variation, particularly in $\mathrm{SO}$ fibres, may be due to heredity, although the genetic components and regulators remain unknown. The key questions are what controls the growth and diversity of fibre types of muscle and are these systems sensitive to impact or manipulations during development that might alter the adult tissue outcome? Given that there is a huge range of size and fibre-type composition of skeletal muscles to fulfil a large range of physiological requirements, the basic process and principles controlling the early development of muscle must be capable of generating muscles with the required diversity of structure and function.

groups of the lower leg from a rat fetus at day 19 of gestation; (b) the dorsal muscle groups of the lower leg from a 3-day-old neonatal rat; (c) the soleus muscle of a weanling rat (19 days old); and (d) the soleus muscle of a 1-year-old rat. Scale bar represents $50 \mu \mathrm{m}$. 


\section{Muscle development}

Discussion of the processes leading to the formation of myogenic cells often uses the terms specification, determination, commitment and differentiation in a number of different contexts. For the purposes of this review, specification is the sequence of events that gradually restricts the fate of the pluripotent mesodermal cells and makes them responsive to signals that lead to their establishment as myogenic precursors cells. Determination, also referred to as commitment, is also a multistep process, at the end of which the cells are determined (usually irreversibly) and have acquired a myogenic identity. Determined cells then differentiate at their final location and start to express a full range of myogenic markers.

\section{Somitogenesis}

One of the earliest steps in the development of vertebrate embryos is somitogenesis (for review, see Rawls et al., 2000) during which epithelial somites form from the anterior end of the segmental plate. During development the somites mature and become compartmentalized to form the sclerotome, myotome and dermomyotome (Fig. 4).

It is well accepted that all vertebrate skeletal muscles (except those of the head) originate from mesodermal precursor cells in the somites, but few studies acknowledge that the specification of the pool of cells that will give rise to skeletal muscle may occur long before somitogenesis. Embryonic cells with the potential to form muscle are present during gastrulation (George-Weinstein et al., 1996, 1997) and, when dissociated cells from the epiblast layer of primitive streak-stage embryos were cultured at high density in serum-free medium, they were shown to express a muscle-specific transcription factor and to differentiate into skeletal muscle (George-Weinstein et al., 1996). These observations point to a basic genetic specification of some muscle precursor cells and to a possible opportunity to alter myogenic outcome by early embryonic manipulation. However, although some of the epiblast cells may function as founder cells for the myogenic lineage, most epiblastic cells are pluripotent, and hence the major commitment to the myogenic lineage appears to occur in the mesodermal somites. In this context, it is of interest that, in zebrafish, separate slow and fast muscle precursor cells have been identified before somite formation (Devoto et al., 1996).

\section{Myogenic regulatory factors}

The discovery in the late 1980s of a factor, the ectopic expression of which resulted in a stable, heritable conversion of non-muscle cells to a myogenic lineage, was a landmark in the understanding of muscle development. Subsequent studies revealed a family of four myogenic regulatory factors (MRFs); myoD, myf5, myogenin and MRF4 (myf6), which can each activate skeletal muscle differentiation when introduced into non-muscle cells. The MRFs are a group of basic helix-loop-helix (bHLH) transcription factors that play a central regulatory function in the skeletal muscle development programme. The function of these four related but distinct MRFs has now been largely worked out through the use of gene knockout experiments (for review, see Ludolph and Konieczny, 1995). The outcome of these experiments is that myoD and myf5 appear to be important for the formation and survival of myoblasts, having redundant function in myoblast specification, whereas myogenin and either myoD or MRF4 seem to be involved in the control of the terminal differentiation in the myotubes (Rawls et al., 1995). Although unravelling the role of the individual MRFs has been complicated by redundancy and crossregulation, studies using triple-mutant mice (lacking myoD, myogenin and MRF4) have revealed that normal numbers of myoblasts form in these mice but differentiation occurs neither in vivo nor in mutant-derived myoblasts in vitro (Valdez et al., 2000). This finding indicates that although myf5 can activate myogenesis in transfection assays and trigger myoblast specification in vivo when expressed alone, in the absence of other MRFs in vivo, it cannot act autonomously to maintain the myogenic programme.

\section{Myogenic identity}

Signals from the neural tube and notochord are important in the control of muscle development, but recently their precise role in the molecular events leading to myogenic commitment and differentiation has started to become clear. Early studies showed that diffusible signals from the dorsal neural tube and the dorsal ectoderm act to organize the dermomyotome (Spence et al., 1996). Signals from the dorsal neural tube induced myf5 expression, whereas those from the dorsal ectoderm induced the expression of myoD (Cossu et al., 1996). More recently molecular messengers have been identified. Sonic hedgehog (Shh), a secreted glycoprotein produced by the notochord and floor plate, has been shown to have an essential inductive function in the early activation of myf5 leading to the determination of epaxial dermomyotomal cells to myogenesis (Borycki et al., 1999). Members of the Wnt family can induce myogenesis (Tajbakhsh et al., 1998). Wnt-1 expressed in the dorsal neural tube preferentially activates Myf5, whereas Wnt-7a expression in the dorsal ectoderm leads to myoD activation. In addition, combined Shh and Wnt-1 signals can induce the expression of the transcription factor Pax3 in the dorsal lip of the dermomyotome (Stern et al., 1995). Somitic myogenesis is also under a negative regulation (Reshef et al., 1998) possibly via bone morphogenic protein 4 (BMP4) signalling, which inhibits the activation of myoD and myf5 in dermomyotomal cells expressing Pax3. BMP4 signalling may be modulated through the action of the BMP antagonist Noggin, which is expressed in the dorsal lip of the dermomyotome (McMahon et al., 1998). The expression of Noggin is, in turn, induced by Wnt-1 produced in the dorsal neural tube (Reshef et al., 1998). These pathways are clearly 


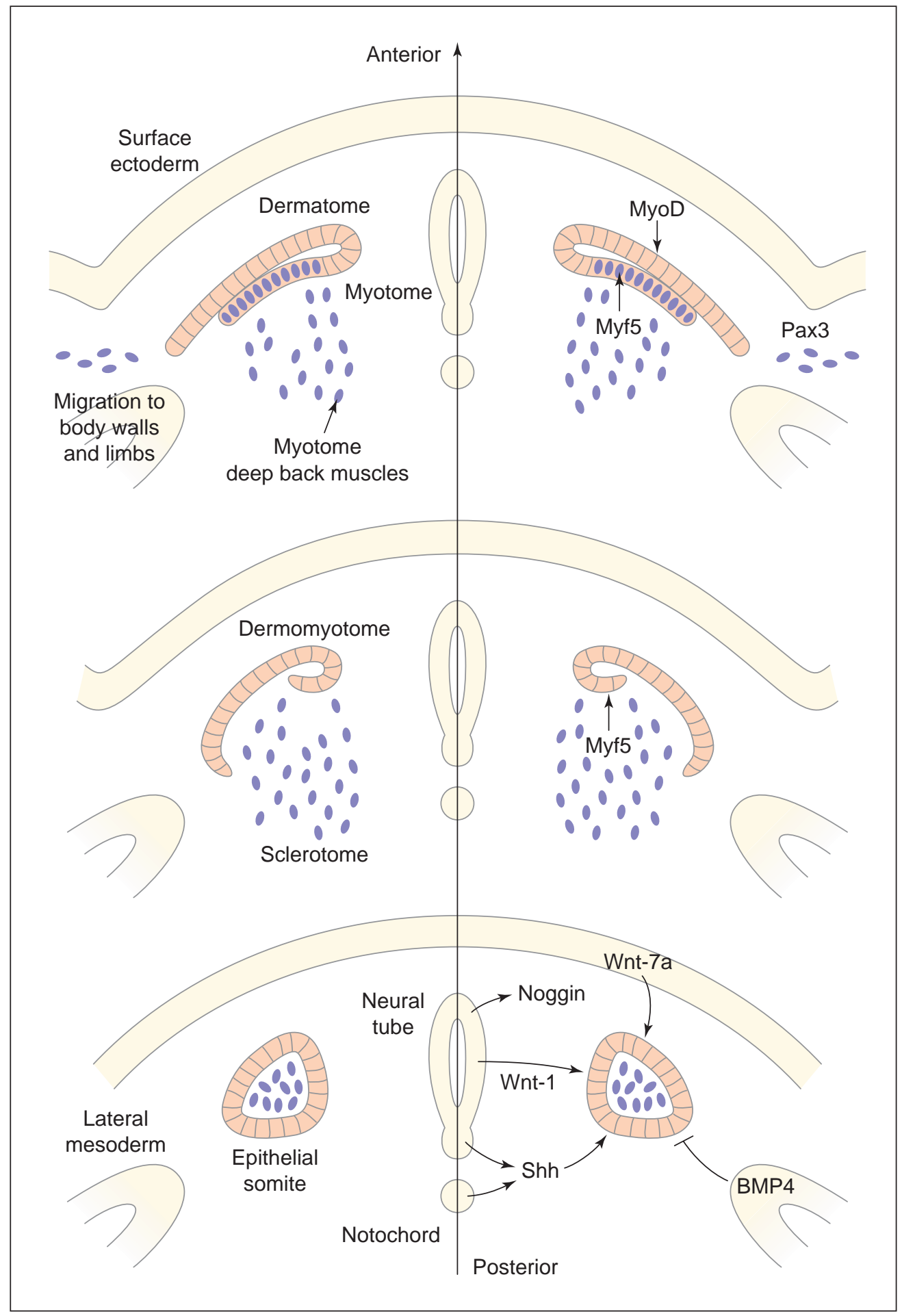

Fig. 4. Illustration of early muscle development. The left-hand side of the figure details the main structural changes during early muscle development; the right-hand side outlines some of the key regulators thought to be involved in myogenic specification, determination and migration of myogenic cells. The mesodermal somites form in a head to tail progression by segmentation of the mesodermal tissue on both sides of the neural tube. Newly formed somites consist of an epithelial ball of cells that becomes arranged into distinct cellular regions as a result of signal arising from surrounding tissues. The ventral region gives rise to the sclerotome from which the ribs and vertebrae form; the dorsal part of the somite forms the dermomyotome, which gives rise to muscles and dermis. Cells from the dorsomedial region of the dermomyotome develop first and eventually form the muscle of the back, whereas cells from the ventrolateral part develop after a 
complex, but results so far indicate that, through the outlined signalling network involving at least Shh, Wnts, BMP4, Noggin and Pax3, precise temporal and spatial regulation can be achieved. (Fig. 4).

These signal pathways lead to determination of the myogenic cells and formation of myogenic precursors cells (MPCs), although a small number of cells are believed to undergo terminal differentiation to form myotomal muscle. Most of the cells remain in an undifferentiated state and, after appropriate migration, will divide and proliferate before the formation of fully differentiated muscle.

\section{Cell migration}

The formation of the limb musculature is particularly interesting because it involves obligatory migration of MPCs from the dermomyotome, where determination occurs, to the limb, where differentiation occurs. Migration depends on the activity of a number of gene products that block the myogenic programme and keep the MPCs in an undifferentiated state so that the onset of myogenesis in the muscles of the limbs and the body walls is delayed. Pax3 is essential for the migration of the MPCs (Goulding et al., 1994), which represses the expression of myoD (Pourquié et al., 1995), but is not necessary for the differentiation of limb muscle precursors (Daston et al., 1996). Therefore, the switch from a Pax3-positive state to the expression of MRFs is a key step in the entrainment of the differentiation process (Pourquié et al., 1995). The c-met ligand scatter factor and hepatocyte growth factor (SF/HGF) also plays a role in the migration of MPC, although not as a chemotactic signal as initially thought. SF/HGF that is expressed adjacent to the dermomyotome causes delamination of the migratory cells from the dermomytomal epithelium (Heymann et al., 1996). Several candidate genes have been proposed to control the migration of the Pax3-positive MPCs (Büscher and Belmonte, 1999), but the genes and mechanism that regulate the progress and positioning of determined MPC from the dermomyotome to the limb remain unknown.

\section{Proliferation versus differentiation}

After the migration of MPCs into the limb buds, the cells undergo rounds of proliferation and increases in the number of cells. At some point, the cells withdraw from the cell cycle and begin the process of cell fusion and maturation. The events that determine the withdrawal from the cell cycle may be critical to the ultimate number of cells in the adult muscle and indeed may influence the number of fibres and hence muscle mass.

The mutual exclusivity of proliferation and differentiation in myogenesis is well recognized (Olson, 1992) and studies have now started to unravel the mechanism by which cell cycle activity blocks terminal differentiation. Myogenic differentiation is highly regulated and shows marked temporal organization (Walsh and Perlman, 1997). Under conditions of growth, myoblasts proliferate and do not express markers of differentiation such as myogenin. In the presence of growth factors: (i) inhibitor of differentiation (Id) is expressed and acts by dimerization with E12 (a member of the E-type family of ubiquitous bHLH transcription factors), which process prevents the heterodimerization between MRF and the E-type factors, hence preventing the binding to the E-box consensus sequence within the muscle-specific promoters; and (ii) protein kinase $C$ is activated, which phosphorylates MRF and inhibits DNAbinding activity. Reduction or removal of mitogens leads to a decrease in Id, thus permitting the formation of bHLH heterodimers, which then bind to their DNA targets and initiate muscle-specific gene transcription (Fig. 5).

A key element in the switch from proliferation to differentiation is cyclin D1, which appears to inhibit myogenic transcription (Skapek et al., 1995), although this inhibition is reversed by retinoblastoma protein ( $\mathrm{pRb}$ ). $\mathrm{pRb}$ is required for the maintenance of the postmitotic state as myogenic cells lacking pRb undergo apoptosis at a high frequency during myogenesis (Wang et al., 1997).

Myogenin, an early marker of entry into the differentiation pathway, is not expressed until proliferating cells experience a low mitogen-containing environment but, despite apparent initiation of the differentiation process, myogenin-positive cells have been shown to retain the capacity to synthesize DNA. However, shortly after the onset of myogenin expression, the cells co-express the cell cycle inhibitor p21 and the ability to synthesize DNA is lost as the cells withdraw irreversibly from the cell cycle (Andres and Walsh, 1996).

\section{Fibre-type diversity}

As the specific proportion of types of fibre within differentiated muscle influences the muscle function, questions central to understanding tissue performance are: what is the origin of fibre-type diversity; how is it controlled at the cellular level; and are there opportunities to manipulate diversity to enhance performance?

Myoblasts that have withdrawn from the cell cycle and

significant delay and eventually migrate into the limb buds to form the musculature of the limbs and body wall. A working model of the proposed pathways has been developed on the basis of current knowledge. The model proposes that Shh from the notochord and the floor plate acts on the ventral domain of the newly formed epithelial somite inducing the formation of the scelerotome and acts on the dorso-medial region of the somite to induce the formation of the medial dermomyotome. Wnt-1 produced by the dorsal neural tube acts in conjunction with Shh on the dorsomedial region and activates myogenesis in the deep back muscle progenitors via a pathway that appears to be myf5-dependant. Wnt-7a from the dorsal ectoderm acts on the dorsolateral domain to specify the body muscle progenitors through a myoD-dependent pathway. In mice, the initial sites of myogenic regulatory factor activation appear distinct, but in chicks, it appears that a myoD-dependent pathway is activated first in the medial somite and this is followed by the activation of a myf5 pathway. 


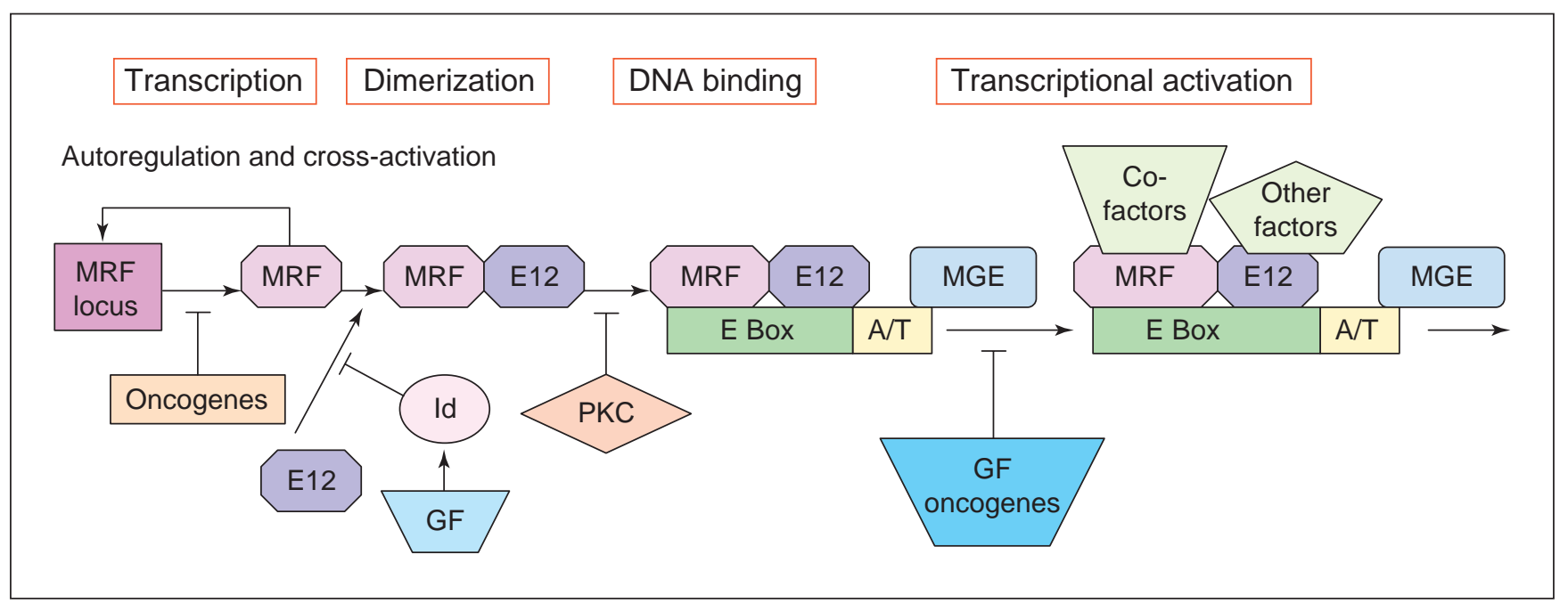

Fig. 5. Schematic representation of myogenic regulatory factor (MRF) regulation of muscle-specific gene expression (MGE). Transcription of each MRF locus may be influenced by positive autoregulation and cross-activation of other MRFs. MRFs form heterodimers with E12 to permit DNA binding at the E Box. Growth factors (GF) influence the formation of MRF-E12 dimers by maintaining high concentrations of the inhibitor Id, which binds E12, and by activating protein kinase C, which phosphorylates MRF and prevents DNA binding. Removal of GF permits heterodimer formation, and transcriptional activation leads to MGE. Activation is shown by arrows, inhibition is shown by bars.

are co-expressing myogenin and p21 start to express MHC and enter the final process of differentiation. The final stage in the formation of muscle fibres is biphasic: the production of new fibres through myoblast fusion occurs in two discrete phases. An initial wave of roughly synchronous fusion of myoblasts gives rise to a population of primary fibres. These primary fibres form early during myogenesis, in rats at about embryonic day 14 (Wigmore and Dunglison, 1998) or in humans between 6 and 8 weeks of gestation (Barbet et al., 1991). Primary fibres are distributed throughout the muscleforming areas in the limb and rapidly increase in size. In rats, chickens, mice and guinea-pigs, the primary fibres represent a small proportion of the final fibres, but they extend from tendon to tendon and form the shape of the muscle.

After primary fibre formation is complete, a second wave of myogenesis begins, and new fibres form on the surface of each primary fibre. These secondary fibres appear asynchronously over a period of days, between embryonic days 17 and 21 in rats (Wigmore and Dunglison, 1998) and between weeks 8 and 18 of gestation in humans (Barbet et al., 1991). The secondary fibres form initially on the surface of the primary fibres, which they use as scaffolding to guide growth towards the tendons (Fig. 6). The number of secondary fibres associated with each primary fibre appears to vary: approximately twice as many secondary fibres per primary fibre occurring in large animals compared with small animals (Stickland and Handel, 1986; Ontell et al., 1988). It has been suggested that these observations support the concept that the large number of fibres in larger animals is achieved through higher numbers of secondary fibres rather than increased numbers of primary fibres (Wigmore and Dunglison, 1998). However, the situation in large animals may be more complex. Studies in sheep and humans (Draeger et al., 1987; Wilson et al., 1992) indicate that at least three generations of myoblasts use the previous generation of myofibres as a scaffolding. Thus, further populations of cells would not only enhance the growth rate of the developing tissue but also contribute to the total number of fibres. This contention begs the question of whether the fundamental mechanisms underlying myogenesis in larger animals are the same as or more complex than those in laboratory animals.

During secondary fibre formation, the primary fibres continue to increase in size and to recruit nuclei. Primary myotubes absorb nuclei at all stages of development, including secondary fibre formation (Zhang and Mclennan, 1995). During the early part of secondary myogenesis, more myoblasts fuse with the primary than with the secondary fibres, but this process is reversed by the end of secondary myogenesis, ensuring that the sarcoplasmic to nuclear ratio is maintained throughout development, although it is unclear what determines whether a cell will fuse with a primary or a secondary fibre.

Initially, the two cohorts of myotubes express different $\mathrm{MHC}$ isoforms. In both pigs and rats, the earliest primary fibres express both slow and embryonic MHC but subsequently, in some of these fibres, this expression is lost and neonatal MHC is expressed. The secondary fibres express embryonic and neonatal MHC, although some of them later switch to slow MHC expression (Condon et al., 1990; Lefaucheur et al., 1995). Many of these changes occur at the time of the innervation that appears to regulate MHC expression (Lefeuvre et al., 1996). Innervation of the primary fibres occurs before the onset of secondary fibre formation as pathfinder axons form multiple synapses along the length of the primary fibres. Secondary myotube 
formation appears to occur around the primary myotube innervation sites (Duxson and Sheard, 1995) and, after embryonic day 17 in rats, this distribution is nonrandom (Wigmore et al., 1996). A signal associated with innervation seems to stimulate the formation of secondary fibres on the surface of the primary fibres. The identity of the signal is unknown but candidates such as acetylcholine, calcitonin gene-related peptide, calcium flux and local changes in membrane potential have been proposed (Duxson and Sheard, 1995). As it is possible that variation in the number of secondary fibres may contribute to the variation in total number of fibres (Dwyer et al., 1994), the exact nature and source of this signal is an important area for future research.

\section{Origin of myoblasts}

The ordered nature of myogenesis has raised the question of whether the cells that contribute to primary and secondary fibre formation have a common or separate embryonic origin and whether, in turn, these different myogenic populations give rise to the fibre-type diversity seen in differentiated muscle. Several studies have demonstrated that the myogenic cells in the limb can be isolated and grouped into at least three populations: embryonic, fetal and adult (or satellite cells) (for example, Stockdale 1992). In human limb buds, for example, four phenotypically distinct populations of myoblasts have been identified at the beginning of primary myogenesis (Edom-Vovard et al., 1999). These populations of myoblasts appear to predominate at different stages of development and are distinguished by their culture requirements, abilities to fuse, sensitivity to growth factors and the morphological nature of the myotubes they form. These various populations are likely to play different roles during myogenesis.

In mammals, the embryonic myoblasts, which are most numerous at the time of primary myogenesis, may be the progenitors of primary fibres and of the SO fibres in adults, whereas fetal and adult myoblasts contribute to secondary fibres and satellite cells in the adult. Retroviral marking of rat myoblasts at embryonic day 15 in vivo (Dunglison et al., 1999) confirmed this contention by showing that embryonic myoblasts contribute only to the formation of primary fibres, all of which initially formed slow fibres, although some later converted to fast fibres. Dunglison et al. (1999) also clarified the fate of fetal and adult myogenic populations, which appeared to be pluripotent, fusing with both primary and secondary fibres to form either fast or slow fibres. However, the signalling mechanisms that regulate these processes are not understood fully.

In zebrafish, in which the embryonic origins of slow and fast fibres have been elucidated (Devoto et al., 1996), the signal mechanisms underlying the determination of slow and fast fibres are being revealed. Slow-twitch fibres develop from presomitic cells adjacent to the notochord, whereas fast-twitch fibres are formed from the rest of the myotome. Members of the hedgehog family $(\mathrm{HH})$ of proteins specifically induce slow-twitch fibres (Norris et al.,

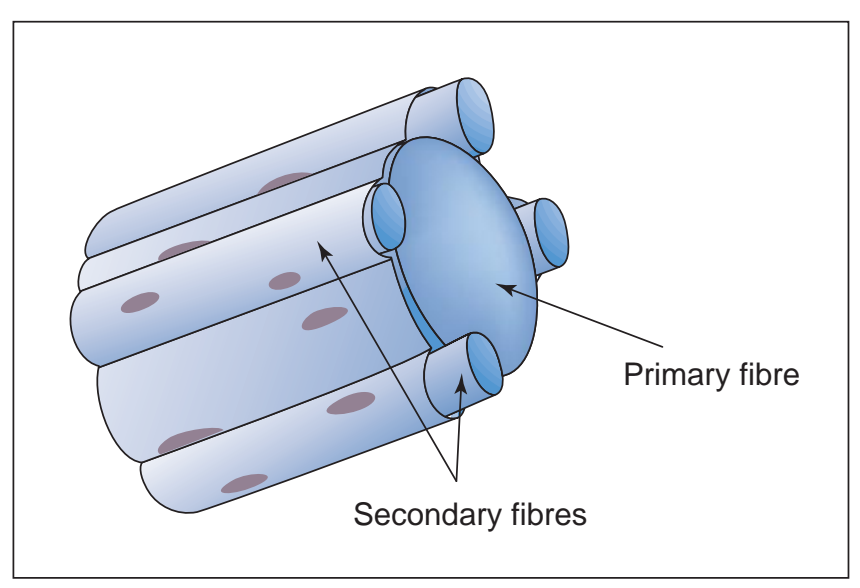

Fig. 6. Illustration of the formation of secondary muscle fibres on the surface of primary fibres.

2000). In contrast, fast fibre formation appears to be $\mathrm{HH}$ independent. The precocious specification of slow fibres in zebrafish differs from that in mammalian embryos; however, as homologous mammalian $\mathrm{HH}$ genes have been reported, it is possible that similar transduction systems in mammals control the specification of slow fibre types.

\section{Regulation and maintenance of fibre-type diversity and fibre size}

The final stage in the establishment of adult muscle continues by fibre conversion and hypertrophy in the postnatal period and displays a characteristic diversity in the type and size of fibres present. Postnatal characteristics of muscle are more dependent on neural and growth factor influences than are prenatal characteristics. Studies have highlighted a new factor that appears to be central to muscle development and growth.

Calcineurin is a $\mathrm{Ca}^{2+}$-calmodulin-regulated serinethreonine phosphatase that plays a pivotal role in the control of muscle signalling pathways regulating multiple muscle events including differentiation (Abbott et al., 1998), hypertrophy (Dunn et al., 1999; Musaro et al., 1999; Semsarian et al., 1999), regeneration (Abbott et al., 1998) and determination of type of fibre (Chin et al., 1998). The effects of activation of calcineurin in muscle are mediated almost invariably through subsequent activation of the nuclear factor of activated T cells (NFAT) family of transcription factors, which together with calcineurin, are highly expressed in muscle (Abbott et al., 1998). Increased intracellular calcium concentrations through insulin-like growth factor I (IGF-I)- or nerve-mediated responses invoke activation of calcineurin, resulting in the binding and dephosphorylation of the NFATs (Rao et al., 1997) (Fig. 7). This action unmasks two nuclear localization sequences, resulting in rapid nuclear translocation (Beals et al., 1997). In the nucleus, NFATs associate with other transcription factors to activate transcription. For example, association with GATA-2 promotes muscle hypertrophy (Musaro et al., 


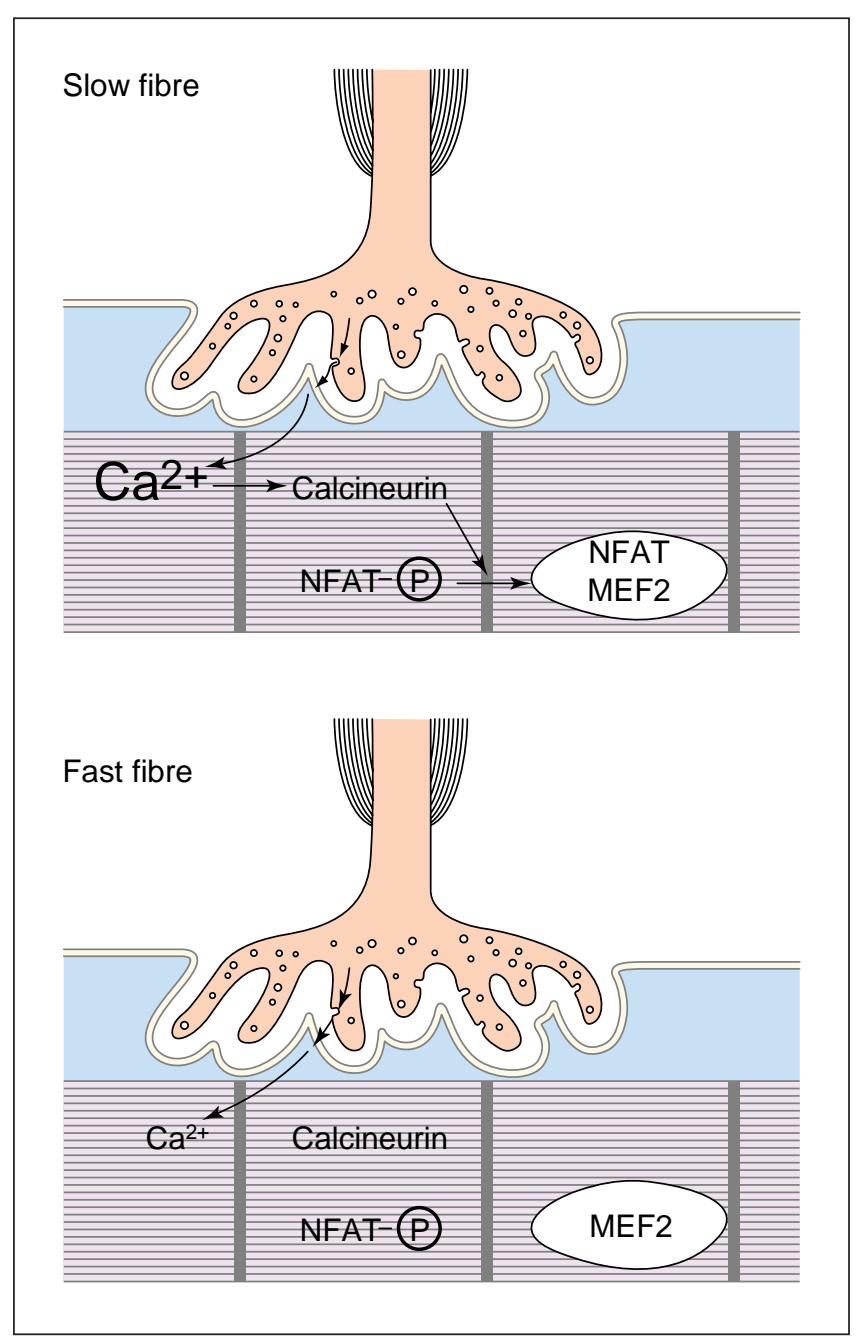

Fig. 7. Illustration of the regulation of calcineurin activity by calcium and the putative calcineurin-mediated determination of muscle fibre type. Diagrams represent motor endplates addressing (a) a slow muscle fibre and (b) a fast fibre. Calcineurin activity is regulated tightly by alterations in intracellular $\mathrm{Ca}^{2+}$ concentration. Slow fibre motorneurons are firing constantly, such that basal intracellular $\mathrm{Ca}^{2+}$ concentrations remain high (100-300 nmol $\mathrm{I}^{-1}$ ) (Hennig and Lomo, 1985), and calcineurin remains active and dephosphorylates NFATs, which are translocated to the nucleus. In contrast, fast fibre neurones fire only sporadically, such that transient calcium spike values leave basal concentrations below $50 \mathrm{nmol} \mathrm{I}^{-1}$ (Westerblad and Allen, 1991), which is insufficient to activate calcineurin and thus NFATS remain phosphorylated. The presence of NFATs in the nucleus of slow fibres allows transcription of slow fibre-specific genes. Conversely, the absence of nuclear NFATs results in fast fibre-specific gene expression.

1999) and association with myocyte enhancer factor 2 (MEF2) and Sp1 induces oxidative or slow fibre-specific myoglobin and troponin $1_{\text {slow }}$ gene expression (Chin et al., 1998). However, calcineurin regulation of muscle differentiation does not involve NFATs (Friday et al., 2000). Instead, calcium and calcineurin are required for the transcriptional activation of myogenin and the initiation of myogenesis (Friday et al., 2000).

As essentially the same calcineurin signalling pathway appears to control both the type and size of muscle fibres, how are signals regulating fibre-type selective expression distinguished from those driving hypertrophy? This question may be resolved by examining the differences in the control of additional signalling pathways modulating calcineurin-regulated transcription or the different threshold concentrations for activating fibre-type expression versus hypertrophy. Furthermore, differences may occur in both the range and abundance of transcriptional activating partners (that is, MEF2, GATA, or AP1 for NFATs) permitting the activation of different sets of downstream target genes.

The hypertrophic processes also depend on the maintenance of the sarcoplasmic:nuclear ratio, which is achieved through the inclusion of nuclei derived from the satellite cells that are retained beneath the basal lamina of differentiated fibres. As these cells are formed during fetal myogenesis and act to regulate long-term hypertrophic potential, the accumulation of satellite cells during development may have critical impact on the realization of hypertrophic potential.

\section{Factors impinging on muscle development to affect adult performance}

Fetal growth and development are limited both by the intrauterine environment and by genetic potential. Experiments with gene knockouts and knockins and in cell culture have revealed a great deal about the mechanistic regulation of myogenesis. However, much less is known about how the intrauterine environment interacts with the genetic potential of the fetus to affect muscle development.

\section{Nutrition}

The impact of maternal nutrition on fetal growth or birth weight is well documented, although not all studies provide specific information on skeletal muscle. In general, severe manipulations of maternal nutrition (for example, starvation or substrate restriction) lead to a reduction in the number of fetal fibres (Wilson et al., 1988; Dwyer and Stickland, 1992) which appears to be irreversible (Prakash et al., 1993), whereas moderate undernutrition tends not to affect muscle development. However, the results of studies in which the number of fibres was reduced indicate that primary fibres are resistant to manipulation, whereas secondary fibres are preferentially affected (Ward and Stickland, 1991; Dwyer and Stickland, 1992). Similarly, in situations in which the number of fibres is increased, it is the number of secondary fibres that appears to change. For example, doubling maternal feed intake during a critical period (days 25-50 of gestation) increased the mean number of secondary fibres formed in pigs (Dwyer et al., 1994). There are a few examples in which natural undernutrition occurs, such as the study by Aberle (1984) in 
which fetal growth retardation owing to placental insufficiency resulted in a reduced number of secondary fibres. In sheep with a low birth weight, the small reduction in muscle mass was not accompanied by a reduction in the number of myofibres, indicating that the number of fibres was set before the effect of the growth retardation occurred (Greenwood et al., 2000).

Several studies have examined the impact of specific restrictions or additions of nutrients. Protein restriction throughout gestation (Desai et al., 1996), reduced body weight and muscle mass up to weaning, and restoration of normal nutrition only partially reversed these effects. However, imposing a protein restriction immediately after birth by cross-fostering has almost as great an effect on body weight and muscle mass as protein restriction from conception to weaning. This finding indicates that there is an early postnatal period during which muscle development is highly sensitive to nutritional insults. During the early postnatal period, maximum gut growth occurs because, with the loss of placental supply, a functional nutrient uptake system via the gut becomes essential. Consequently, any manipulation to take advantage of the apparent sensitivity of muscle during this period must acknowledge the potential of any impact on gut growth.

Maternal undernutrition can restrict the efficiency and size of the placenta, which may affect fetal-neonatal outcome because the placenta is crucial in providing an environment that supports optimal fetal growth through nutrient supply, waste removal, immune and pathogen protection and the production of hormones and growth factors, some of which may act to modulate fetal IGF-I. The importance of IGF-I in fetal development has been postulated for a long time (for review, see Gluckman, 1995) and IGF-I has also been implicated in fetal reprogramming. A study in sheep has shown that maternal periconceptual undernutrition reprogrammes IGF-binding protein 3 (IGFBP3) and IGF-I regulation in the developing fetus, so that subsequent responses to undernutrition in late gestation are altered (Gallaher et al., 1998). Although no information relating to skeletal muscle was presented in this report, the findings may explain other observations. IGF-I is a potent mitogen, implicated in the regulation of cell proliferationdifferentiation and protein anabolism. Thus, any periconceptual reprogramming of IGF responsiveness owing to undernutrition might alter myogenesis and account for some of the observed reductions in the number of fibres after early undernutrition.

Thinness at birth has been linked to an increased risk of insulin resistance in adult life (Phillips et al., 1994). The mechanistic basis of this relationship is not clear, but because muscle is a major target of insulin action it was speculated that reduced muscle growth in utero may alter developmental programming and perturb insulin action. However, fetal undernutrition was not associated with abnormal muscle histology or blood flow, and the metabolic performance of several key muscle enzymes was normal (Thompson et al., 1997); rather it appeared that a low ponderal index (birthweight/length ${ }^{3}$ ) was associated with increased muscle oxygen supply.

Vitamin A is essential for normal embryogenesis (for review, see Ross et al., 2000). The biological activity of vitamin A depends on its conversion to retinoic acid and the enzymes thought to be responsible for retinoic acid production have been identified in the limbs and somites of rat embryos, demonstrating that vitamin $\mathrm{A}$ is converted to its active form in embryos (Bavik et al., 1997). The function of retinoic acid in mammalian embryonic myogenesis is not extensively documented, but in chick limbs, it appears to play an important role in the control of muscle patterning (Duprez et al., 1999). In regenerating axolotl limbs, retinoic acid appears to induce the expression of Shh (Torok et al., 1999) and it is possible that similar responses occur in the early embryo to underpin the control of patterning (Ross et al., 2000). Studies of myogenesis in vitro show that retinoicacid-induced growth arrest and differentiation in myoblasts is mediated largely through retinoid $X$ receptors (Downes et al., 1994). Retinoic acid acts in a dose-dependent manner to reduce myf5 gene transcription (Carnac et al., 1993), whereas the expression of myoD in myoblasts and myogenin in clonal rhabdomyosarcoma cells appears to be inducible by retinoic acid (Arnold et al., 1992; Alric et al., 1998). Although addition of exogenous retinoic acid to myoblasts in vitro does influence myogenesis, how variations in maternal concentrations of vitamin A impact on muscle development and patterning in the embryo remains unclear.

Taken together, these data indicate that early myogenesis is well protected against nutritional insult, which may reflect a strategy to ensure neonatal viability in times of nutritional stress. The data also support the contention of programming of the number of primary fibres (and hence the number of SO fibres), but indicate that both the number of secondary fibres and early postnatal muscle growth are sensitive to nutrient manipulation.

\section{Effects of hormones, growth factors and environment}

Hormones are central to the regulation of muscle growth and the regulation of fibre type (Walker and Luff, 1995). For example, administration of pig somatotrophin (pST) to sows early during gestation (between day 10 and day 24) increases the number of fetal muscle fibres (Rehfeldt et al., 1993). Administration of pST later during gestation (between day 28 and day 48) not only alters embryonic development but also affects early postnatal growth of piglets (Kelley et al., 1995). In the study of Kelley et al. (1995), embryonic survival, neonatal length, muscle mass and muscle cross-sectional area were increased, whereas back fat thickness was reduced, consistent with no change in birth weight. In addition, maternal uterine IGF-I expression appears to increase in treated sows, whereas fetal muscle myf5 expression is repressed and myogenin expression enhanced at day 41 of gestation. These findings indicate that myogenic hyperplasia is stimulated during somitogenesis and is consistent with the stimulation of Id 
expression by pST (Mulvaney et al., 1996). Single time point analyses are not particularly informative in a developmental situation; however, these findings do indicate an impact of pST treatment on myogenic gene expression programmes at the interface between proliferation and differentiation in the fetus with resultant changes in neonatal muscle. Although these data were not presented in these papers, information pertaining to treatment-related changes in muscle fibre might show an increase in the number of fibres in treated animals underlying the observed increase in muscle mass.

Experimentally induced hypothyroidism in pregnant mice induced a complete inhibition of postnatal muscle fibre type differentiation in the neonates (d'Albis et al., 1987), whereas neonatal hyperthyroidism accelerated adult fast fibre type formation. Thus, there may be a window of sensitivity to stimuli early during development. Thyroid hormone also appears to work in conjunction with innervation mainly after birth (d'Albis et al., 1990) to regulate fibre-type profiles and establish full realization of the phenotypic potential (White and Dauncey, 1999).

Synthetic $\beta_{2}$ adrenoceptor agonists that mimic the action of adrenaline have also been shown to affect myogenesis in vivo. Administration of clenbuterol to rats early during gestation reduces fetal weight and decreases secondary: primary fibre ratio, and leads to a reduction in muscle mass, protein, RNA and DNA content and total number of fibres after birth (Maltin et al., 1990). These observations raise the question, pertinent to both animals and humans, as to whether high maternal concentrations of endogenous or exogenous $\beta_{2}$ agonists during early pregnancy have an effect on fetal myogenesis.

Further evidence detailing changes in myogenesis resulting from early embryonic insults supports the contention that events occurring before pregnancy is fully established can alter muscle growth and development, and also raises questions about the timing of myoblastic diversity. Two studies that used embryo transfer techniques (asynchronous transfer and co-culture, Maxfield et al., 1998a,b) showed that preimplantation events could alter both the total number of fibres and the secondary: primary fibre ratio. The sensitivity of fetal myogenesis to procedures applied before implantation may support the concept that a pool of cells is specified to become muscle before the onset of somitogenesis. The mechanistic basis for these results is not clear, but it has implications in relation to technologies involving the manipulation of early embryos and may explain the fetal outcomes observed arising from the use of artificially produced or transferred embryos (Kruip and den Daas, 1997).

The embryo manipulation studies highlight again the observation that primary fibres appear to be resistant to manipulation. Thus, there is a body of data now indicating that not only are primary fibres genetically programmed, but that their programming does not appear to be affected by exogenous influences. From the point of view of the animal and in terms of the basic survival of the neonates, the protection of these fibres makes sense, as their presence in the limb musculature at least provides the means for the animal to maintain its position in gravity. Indeed, some animals such as the slow loris have few, if any, fast fibres (Ariano et al., 1973).

It has been suggested that myostatin, a negative regulator of muscle mass, is important during primary and secondary fibre formation, as increased transcript concentrations have been noted around this period in pigs (Ji et al., 1998). This suggestion is of interest because mutations in the myostatin gene are the cause of double muscling (resulting from an increased number and size of fibres) in cattle (McPherron and Lee, 1997), but it is not known whether the lack of myostatin affects both primary and secondary fibres in these animals. In mouse embryogenesis, myostatin is expressed in the somitic domain, which gives rise to skeletal muscle (Lee and McPherron, 1999), so it is not clear whether myostatin acts at this early stage to regulate the number of fibres, or whether later expression regulates prenatal fibre growth. Lee and McPherron (1999) proposed that, in its role to regulate muscle mass, myostatin functions as a 'chalone' (a secreted molecule that inhibits cellular function). Myostatin has to meet a number of functional prerequisites in order to be considered as a 'chalone', one of which is that myostatin should circulate in vivo. Although this possibility is explored, the intriguing observation that when fetuses with different genetic propensity for muscle development are twinned in utero, there is a reduction in the muscle mass but an apparent increase in the number of fibres in the heavier muscled fetus (Gerrard et al., 1995) should be considered. If myostatin is a 'chalone' and is produced by the less muscled animals, then this might account for the reduction in muscle mass seen in the heavier muscled animals. Although the apparent increase in the number of fibres is not consistent with this hypothesis, close examination of the methods used to make this estimate (Gerrard and Judge, 1993) including the measurement of muscle circumference by tape measure, indicate that the estimate may be unreliable.

Transformations of fibre type and postnatal hypertrophy clearly affect the performance of the muscle in adults and, therefore, may be more sensitive to manipulation. Postnatal hypertrophy may also be influenced by innervation and thyroid hormone, since it appears that hypothyroidism early during postnatal life inhibits the incorporation of satellite cells into existing fibres, thereby reducing the growth potential of the muscle (Jacobs et al., 1996). Thus, while some of the key factors (for example, hormones, innervation) that influence muscle in this sensitive postnatal period have been identified, a greater understanding of the postnatal regulation and maintenance of muscle characteristics is required to achieve targeted manipulation of muscle.

\section{Genetic selection}

Optimal muscle mass is often the commercial endpoint in agriculture. Animal breeding strategies (Robinson and Bradford, 1969) for meat production have focussed on 
selecting for muscle mass and growth rate and, during this process, many have selected increases in the numbers and size of fibres, indicating that these traits are heritable. This heritability has been noted in commercial populations of pigs, in which divergent selection has produced populations with different muscle fibre proportions, particularly with respect to FG and SO fibres (Maltin et al., 1997). Many 'improvements' in muscle have been made on the basis of achieving increased muscle mass in the adult. For example, the P-line quail (Coutinho et al., 1993) has been developed through selection procedures for increased body weight, which has been achieved through an increased number of fibres. Increased numbers of fibres is associated with delayed somite formation and delayed expression of MRFs and MHC. Genetic selection is a powerful means by which to manipulate the performance potential of muscle. However, in most species this is not a rapid procedure and, in some cases, it is possible that selection has taken muscle to its full genetic potential. The rather arbitrary nature of the selection criteria (for example, muscle mass in livestock species rather than eating quality) is also a concern. If genetic 'improvement' of muscle is to be achieved, then greater understanding of the regulation of the performance parameters to be 'improved' is needed, so that detection and selection strategies for the key genes can be developed.

\section{Conclusions and implications}

Muscle mass and function are important for life. Muscle development starts early during embryogenesis and factors that impinge on the developing fetus can affect muscle development. The major impacts on myogenesis thus far identified appear to be associated with extremes of treatments or embryo manipulations, in which cases responses are seen predominantly in the secondary fibres and the primary fibres appear insensitive or protected. The mechanistic basis of this differential responsiveness is not known.

Many questions surround the relationship of muscle development with adult performance, not least of which is how the apparent heritability of fibre types affects performance and developmental sensitivity. Evidence indicates that the composition of muscle fibre types has a heritable component, particularly with respect to SO fibres that are largely derived from primary fibres. Is this proposed genetic control the underlying mechanism or reason for the insensitivity of primary fibres to insults? If the evidence of heritability is fully substantiated, then the evidence in humans and livestock species indicates that it would be beneficial to be able to select for or manipulate the numbers of SO fibres. Thus, the search for the genotypic basis of SO-primary fibre formation would become one of the Holy Grails in modern muscle biology.

This review has highlighted the limitations of opportunities for the manipulation of myogenesis to improve adult muscle performance. Most manipulations reported to date have not benefited adult muscle performance but have reduced the number of fibres or increased fatiguability.
Although the number of muscle fibres can be increased through embryo manipulations or pST administration, it is doubtful whether this strategy, with the attendant problems of dystocia and welfare issues, is a wise one. Although early myogenesis is largely unaffected by all but extreme insults, early postnatal muscle growth may be susceptible to impacts that affect adult performance. As most muscle growth and fibre type transformations occur after birth, postnatal muscle growth and development is a key area of investigation for the future.

The authors are grateful to Heather Delday for the original drawings in this review. The authors are funded by the Scottish Executive Environment and Rural Affairs Department.

\section{References}

Abbott KL, Friday BB, Thaloor D, Murphy TJ and Pavlath GK (1998) Activation and cellular localization of the cyclosporine A-sensitive transcription factor NF-AT in skeletal muscle cells Molecular Biology of the Cell 9 2905-2916

Aberle AD (1984) Myofiber differentiation in skeletal muscles of newborn runt and normal weight pigs Journal of Animal Science 59 1651-1656

Abernethy PJ, Thayer R and Taylor AW (1990) Acute and chronic responses of skeletal muscle to endurance and sprint exercise: a review Sports Medicine 10 365-389

Aloia JF, Vaswani A, Feuerman M, Mikhail M and Ma R (2000) Differences in skeletal and muscle mass with aging in black and white women American Journal of Physiology, Endocrinology and Metabolism 278 E1153-E1157

Alric S, Froeschle A, Piquemal D, Carnac G and Bonnieu A (1998) Functional specificity of the two retinoic acid receptor RAR and RXR families in myogenesis Oncogene 16 273-282

Andres V and Walsh K (1996) Myogenin expression, cell cycle withdrawal and phenotypic differentiation are temporally separable events that precede cell fusion upon myogenesis Journal of Cell Biology 132 657-666

Aoyagi Y and Shephard RJ (1992) Aging and muscle function Sports Medicine 14 376-396

Ariano MA, Armstrong RB and Edgerton VR (1973) Hindlimb muscle fiber populations of five mammals Journal of Histochemistry and Cytochemistry 21 51-55

Arnold HH, Gerharz CD, Gabbert HE and Salminen A (1992) Retinoic acid induces myogenin synthesis and myogenic differentiation in the rat rhabdomyosarcoma cell line BA-Han-1C Journal of Cell Biology 118 $877-887$

Barbet JP, Thornell LE and Butler-Browne GS (1991) Immunocytochemical characterisation of two generations of fibers during the development of the human quadriceps muscle Mechanisms of Development 35 3-11

Barker DJP (1996) Growth in utero and coronary heart disease Nutrition Reviews 54 S1-S7

Battram JC and Johnston IA (1991) Muscle growth in the antarctic teleost, notothenia-neglecta (nybelin) Antarctic Science 3 29-33

Bavik C, Ward SJ and Ong DE (1997) Identification of a mechanism to localize generation of retinoic acid in rat embryos Mechanisms of Development 69 155-67

Beals CR, Clipstone NA, Ho SN and Crabtree GR (1997) Nuclear localization of NF-ATc by a calcineurin-dependent, cyclosporinsensitive intramolecular interaction Genes and Development 11 824-834

Borycki A-G, Brunk B, Tajbakhsh S, Buckingham M, Chiang C and Emerson P, Jr (1999) Sonic hedgehog controls epaxial muscle determination through Myf5 activation Development 126 4053-4063

Büscher D and Izpisua Belmonte JC (1999) Muscle development during vertebrate limb outgrowth Cell and Tissue Research 296 131-139 
Caccia MR, Harris JB and Johnson MA (1979) Morphology and physiology of skeletal muscle in aging rodents Muscle and Nerve 2 202-212

Carnac G, Albagli-Curiel O, Levin A and Bonnieu A (1993) 9-cis-retinoic acid regulates the expression of the muscle determination gene Myf5 Endocrinology 133 2171-2176

Carpenter CE, Rice OD, Cockett NE and Snowder GD (1996) Histology and composition of muscles from normal and callipyge lambs Journal of Animial Science 74 388-393

Chin ER, Olson EN, Richardson JA, Yang Q, Humphries C, Shelton JM, Wu H, Zhu W, Bassel-Duby R and Williams RS (1998) A calcineurindependent transcriptional pathway controls skeletal muscle fiber type Genes and Development 12 2499-2509

Condon K, Silberstein L, Blau HM and Thompson WJ (1990) Development of muscle fiber types in the prenatal rat hindlimb Developmental Biology 138 256-274

Cossu G, Kelly R, Tajbakhsh S, Di Donna S, Vivarelli E and Buckingham M (1996) Activation of different myogenic pathways myf-5 is induced by the neural tube and MyoD by the dorsal ectoderm in mouse paraxial mesoderm Development 122 429-437

Costill DL, Daniels J, Evans W, Fink W, Krahenbuhl G and Saltin B (1976) Skeletal muscle enzymes and fiber composition in male and female track athletes Journal of Applied Physiology 40 149-154

Coutinho LL, Morris J, Marks HL, Buhr RJ and Ivarie R (1993) Delayed somite formation in a quail line exhibiting myofiber hyperplasia is accompanied by delayed expression of myogenic regulatory factors and myosin heavy chain Development 117 563-569

d'Albis A, Lenfant-Guyot M, Janmot C, Chanoine C, Weinman J and Gallien CL (1987) Regulation by thyroid hormones of terminal differentiation in the skeletal dorsal muscle I. Neonate mouse Developmental Biology 123 25-32

d'Albis A, Chanoine C, Janmot C, Mira J-C and Couteaux R (1990) Musclespecific response to thyroid hormone of myosin isoform tansitions during rat postnatal development European Journal of Biochemistry 193 155-161

Daston G, Lamar E, Olivier M and Goulding M (1996) Pax-3 is necessary for migration but not differentiation of limb muscle precursors in the mouse Development 122 1017-1027

Desai M, Crowther NJ, Lucas A and Hales CN (1996) Organ-selective growth in the offspring of protein-restricted mothers British Journal of Nutrition 76 591-603

Devoto SH, Melancon E, Eisen JS and Westerfield M (1996) Identification of separate slow and fast muscle precursor cells in vivo, prior to somite formation Development 122 3371-3380

Downes M, Mynett-Johnson L and Muscat GE (1994) The retinoic acid and retinoid $\mathrm{X}$ receptors are differentially expressed during myoblast differentiation Endocrinology 134 2658-2661

Draeger A, Weeds AG and Fitzsimons RB (1987) Primary, secondary and tertiary myotubes in developing skeletal muscle a new approach to the analysis of human myogenesis Journal of Neurological Sciences $\mathbf{8 1}$ 19-43

Duckett SK, Snowder GD and Cockett NE (2000) Effect of the callipyge gene on muscle growth, calpastatin activity and tenderness of three muscles across the growth curve Journal of Animal Science $\mathbf{7 8}$ 2836-2841

Dunglison GF, Scotting PJ and Wigmore PM (1999) Rat embryonic myoblasts are restricted to forming primary fibres while later myogenic populations are pluripotent Mechanisms of Development 87 11-19

Dunn SE, Burns JL and Michel RN (1999) Calcineurin is required for skeletal muscle hypertrophy Journal of Biological Chemistry 274 21 908-21912

Duprez D, Fournier-Thibault C and Le Douarin N (1998) Sonic hedgehog induces proliferation of committed skeletal muscle cells in the chick limb Development 125 495-505

Duxson MJ and Sheard PW (1995) Formation of new myotubes occurs exclusively at the multiple innervation zones of an embryonic large muscle Developmental Dynamics 204 391-405

Dwyer CM and Stickland NC (1992) Does the anatomical location of a muscle affect the influence of undernutrition on muscle fibre number? Journal of Anatomy 181 373-376

Dwyer CM, Stickland NC and Fletcher JM (1994) The influence of maternal nutrition on muscle fiber number development in the porcine fetus and on subsequent postnatal growth Journal of Animal Science 72 911-917

Eddinger TJ, Moss RL and Cassens RG (1985) Fiber number and type composition in extensor digitorum longus, soleus and diaphragm muscles with aging in Fisher 344 rats Journal of Histochemistry and Cytochemistry 33 1033-1041

Edom-Vovard F, Mouly V, Barbet JP and Butler-Browne GS (1999) The four populations of myoblasts involved in human limb muscle formation are present from the onset of primary myotube formation Journal of Cell Science 112 191-199

Fenn WO and MarshB S (1935) Muscular force at different speeds of shortening Journal of Physiology 85 277-395

Friday BB, Horsley V and Pavlath GK (2000) Calcineurin activity is required for the intiation of skeletal muscle differentiation Journal of Cell Biology $149657-665$

Gallaher BW, Breier BH, Keven CL, Harding JE and Gluckman PD (1998) Fetal programming of insulin-like growth factor (IGF)-1 and IGF-binding protein 3: evidence for an altered response to undernutrition in late gestation following exposure to periconceptual undernutrition in the sheep Journal of Endocrinology $\mathbf{1 5 9} 501-508$

George-Weinstein M, Gerhart J, Reed R, Flynn J, Callihan B, Mattiacci M, Miehle C, Lash JW and Weintraub H (1996) Skeletal myogenesis the preferred pathway of chick embryo epiblast cell in vitro. Developmental Biology 173 279-291

George-Weinstein M, Gerhart J, Blitz J, Simak E and Knudsen KA (1997) Ncadherin promotes the commitment and differentiation of skeletal muscle precursor cells Developmental Biology 185 14-24

Gerrard DE and Judge MD (1993) Induction of myoblast proliferation in L6 myoblast cultures by fetal serum of double-muscled and normal cattle Journal of Animal Science 71 1464-1470

Gerrard DE, Grant AL, Anderson DB, Lemenager RP and Judge MD (1995) In vivo analysis of serum-borne growth factors in developing co-twinned fetuses Journal of Animal Science 73 1689-1693

Gluckman PD (1995) Clinical review 68. The endocrine regulation of fetal growth in late gestation the role of insulin-like growth factors Journal of Clinical Endocrinology and Metabolism 80 1047-1050

Gollnick PD, Armstrong RB, Saubert CW, Piehl K and Saltin B (1972) Enzyme activity and fiber composition in skeletal muscle of untrained and trained men Journal of Applied Physiology 33 312-319

Goulding M, Lumsden A and Paquette AJ (1994) Regulation of Pax-3 expression in the dermomyotome and its role in muscle development Development 120 957-971

Greenwood PL, Hunt AS, Hermanson JW and Bell AW (2000) Effects of birth weight and postnatal nutrition on neonatal sheep II. Skeletal muscle growth and development Journal of Animal Science 78 50-61

Grizard J, Picard B, Dardevet D, Balage M and Rochon C (1999) Regulation of muscle growth and development. In Protein Metabolism and Nutrition, Proceedings of the VIIIth International Symposium of Protein Metabolism and Nutrition pp 177-203 Eds GE Lobley, A White and JC MacRae, EAAP Publication No 96, Wageningen, Pers

Harris T (1997) Muscle mass and strength relation to function in population studies Journal of Nutrition 127 1004S-1006S

Hennig R and Lomo T (1985) Firing patterns of motor units in normal rats Nature 314 164-166

Heymann S, Koudrova M, Arnold H-H, Köster M and Braun T (1996) Regulation and function of SF/HGF during migration of limb muscle precursor cells in chicken Developmental Biology 180 566-578

Hughes SM and Schiaffino S (1999) Control of muscle fibre size a crucial factor in ageing Acta Physiologica Scandinavica 167 307-312

Hultman G, Nordin M, SarasteH and Ohlsen H (1993) Body composition, endurance, strength, cross-sectional area and density of MM erector spinase in men with and without low back pain Journal of Spinal Disorders 6 114-123

Jacobs SC, Bar PR and Bootsma AL (1996) Effect of hypothyroidism on satellite cells and postnatal fiber development in the soleus muscle of rat Cell and Tissue Research 286 137-44

Ji S, Losinski RL, Cornelius SG, Frank GR, Willis GM, Gerrard DE, Depreux FF and Spurlock ME (1998) Myostatin expression in porcine tissues 
tissue specificity and developmental and postnatal regulation American Journal of Physiology 275 R1265-R1273

Joubert DM (1956) An analysis of factors influencing post-natal growth and development of the muscle fibre Journal of Agricultural Science $\mathbf{4 7}$ 59-102

Karlsson A, Enfalt A-C, Essen-Gustavsson B, Lundstrom K, Rydhmer L and Stern S (1993) Muscle histochemical and biochemical properties in relation to meat quality during selection for increased lean tissue growth rate in pigs Journal of Animal Science 71 930-938

Kelley RL, Jungst SB, Spencer TE, Owsley WF, Rahe CH, Mulvaney DR and Koch RM (1995) Maternal treatment with somatotropin alters embryonic development and early postnatal growth of pigs Domestic Animal Endocrinology 12 83-94

Koch RM, Jung HG, Crouse JD, Varel VH and Cundiff LV (1995) Growth, digestive capability, carcass and meat characteristics of Bison bison, Bos taurus and Bos $\times$ Bison. Journal of Animal Science 73 1271-1281

Komi PV, Viitasalo JH, Havu M, Thorstensson A, Sjodin B and Karlsson J (1977) Skeletal muscle fibres and muscle enzyme activities in monozygous and dizygous twins of both sexes Acta Physiologica Scandinavica $100385-92$

Kruip ThAM and den Daas JHG (1997) In vitro produced and cloned embryos effects on pregnancy, parturition and offspring Theriogenology 47 43-52

Lee S-J and McPherron AC (1999) Myostatin and the control of skeletal muscle mass Current Opinion in Genetics and Development 9 604-607

Lefaucheur L, Edom F, Ecolan P and Butler-Browne GS (1995) Pattern of muscle fiber type formation in the pig Developmental Dynamics 203 $27-41$

Lefeuvre B, Crossin F, Fontaine-Pérus J, Bandman E and Gardahaut M-F (1996) Innervation regulates myosin heavy chain isoform expression in developing skeletal muscle fibers Mechanisms of Development $\mathbf{5 8}$ 115-127

Lobley GE, Sinclair KD, Grant CM, Miller LA, Mantle D, Calder AG, Warkup CC and Maltin CA (2000) The effects of breed and level of nutrition on whole body and muscle protein metabolism in pure-bred Aberdeen Angus and Charolais beef steers British Journal of Nutrition 84 275-284

Ludolph DC and Konieczny SF (1995) Transcription factor families muscling in on the myogenic program FASEB Journa/ 9 1595-1604

McMahon JA, Takada S, Zimmerman LB, Fan C-M, Harland RM and McMahon AP (1998) Noggin-mediated antagonism of BMP signaling is required for growth and patterning of the neural tube and somite Genes and Development 12 1438-1452

McPherron AC and Lee S-J (1997) Double muscling in cattle due to mutations in the myostatin gene Proceedings of the National Academy of Sciences USA 9412 457-12 461

McPherron AC, Lawler AM and Lee SJ (1997) Regulation of skeletal muscle mass in mice by a new TGF-beta superfamily member Nature 387 83-90

Maltin CA and Wilson AB (1985) Rat diaphragm changes in muscle fiber type frequency with age Muscle and Nerve 8 211-216

Maltin CA, Delday MI and Hay SM (1990) The effect of clenbuterol administration in utero and throughout lactation on pre- and post-natal muscle development in the rat Growth Development and Aging $\mathbf{5 4}$ $143-150$

Maltin CA, Warkup CC, Matthews KR, Grant CM, Porter AD and Delday MI (1997) Pig muscle fibre characteristics as a source of variation in eating quality Meat Science 47 237-248

Maltin CA, Steven JS and Warkup CC (1998a) Assay for Duroc muscle fibre type International Application Published under the Patent Cooperation Treaty International Publication Number, WO 98/1583716 April 1998

Maltin CA, Sinclair KD, Warriss PD, Grant CM, Porter AD, Delday MI and Warkup CC (1998b) The effect of age at slaughter, genotype and finishing system on the biochemical properties, muscle fibre type characteristics and eating quality of bull beef from suckled calves Animal Science 66 341-348

Maltin CA, Lobley GE, Grant CM, Miller LA, Kyle DJ, Horgan GW, Matthews KR and Sinclair KD (2001) Factors influencing beef eating quality II. Effects of nutritional regimen and genotype on muscle fibre characteristics Animal Science 72 279-287

Mannion AF, Weber BR, Dvorak J, Grob D and Müntener M (1997) Fibre type characteristics of the lumbar paraspinal muscles in normal healthy subjects and in patients with low back pain Journal of Orthopaedic Research 15 881-887

Maxfield EK, Sinclair KD, Broadbent PJ, McEvoy TG, Robinson JJ and Maltin CA (1998a) Short-term culture of ovine embryos modifies fetal myogenesis American Journal of Physiology 274 E1121-E1123

Maxfield EK, Sinclair KD, Dunne LD, Broadbent PJ, Robinson JJ, Kyle DG and Maltin CA (1998b) Temporary exposure of ovine embryos to an advanced uterine environment does not affect fetal weight but alters fetal muscle development Biology of Reproduction 59 321-325

Monemi M, Eriksson P-O and Thornell L-E (1998) Adverse changes in fibre type composition of the human masseter versus biceps brachii muscle during aging Journal of Neurological Sciences 154 35-48

More O'Ferrall G and Cunningham EP (1974) Heritability of racing performance in thoroughbred horses Livestock Production Science 1 87-97

Mulvaney DR, Kelley RL, Owsley WF, Jungst SB, Mikel WB, Wolfe DD and Powe T (1996) Use of maternal pST treatment to manipulate fetal muscle development of progeny from terminal and maternal genotype matings Research Report for National Pork Producers Council USA pp 355-365 http//www.nppc.org

Musaro A, McCullagh KJ, Naya FJ, Olson EN and Rosenthal N (1999) IGF-1 induces skeletal myocyte hypertrophy through calcineurin in association with GATA-2 and NF-ATc1 Nature 400 581-585

Nimmo MA, Wilson RH and Snow DH (1985) The inheritance of skeletal muscle fibre composition in mice Comparative Biochemistry and Physiology 81A 109-115

Norris W, Neyt C, Ingham PW and Currie PD (2000) Slow muscle induction by Hedgehog signalling in vitro Journal of Cell Science $\mathbf{1 1 3}$ 2695-2703

Ockerman HW, Jaworek D, VanStavern B, Parrett N and Pierson CJ (1984) Castration and sire effects on carcase traits, meat palatability and muscle fibre characteristics in Angus cattle Journal of Animal Science 59 981-990

Olson EN (1992) Interplay between proliferation and differentiation within the myogenic lineage Developmental Biology 154 261-272

Olson EN and Williams RS (2000) Remodeling muscles with calcineurin Bioessays 22 510-509

Ontell M, Bourke D and Hughes D 1988 Cytoarchitecture of the fetal murine soleus muscle American Journal of Anatomy 181 267-288

Phillips DW, Barker DJP, Hales CN, Hirst S and Osmond CB (1994) Thinness at birth and insulin resistance in adult life Diabetologia 37 150-154

Pourquié O, Coltey M, Bréant C and Le Douarin NM (1995) Control of somite patterning by signals from the lateral plate Developmental Biology 92 3219-3223

Prakash YS, Fournier M and Sieck GC (1993) Effects of prenatal undernutrition on developing rat diaphragm Journal of Applied Physiology 75 1044-52

Proctor DN, Balagopal P and Nair KS (1998) Age-related sarcopenia in humans is associated with reduced synthetic rates of specific muscle proteins Journal of Nutrition 128 351S-355S

Rantanen T, Harris T, Leveille SG, Visser M, Foley D, Masaki K and Guralnik JM (2000) Muscle strength and body mass index as long-term predictors of mortality in initially healthy men Journal of Gerontology 55A M168-M173

Rao A, Luo C and Hogan PG (1997) Transcription factors of the NFAT family regulation and function Annual Review of Immunology 15 707-747

Rawls A, Morris JH, Rudnicki M, Braun T, Arnold H-H, Klein WH and Olson EN (1995) Myogenin's functions do not overlap with those of MyoD or Myf-5 during mouse embryogenesis Developmental Biology $17237-50$

Rawls A, Wilson-Rawls J and Olson N (2000) Genetic regulation of somite formation Current Topics in Developmental Biology 47 131-154

Rehfeldt C, Fiedler I, Weikard R, Kanitz E and Ender K (1993) It is possible to increase skeletal muscle fibre number in utero. Bioscience Reports 13 213-220

Remignon H, Gardahaut MF, Marche G and Ricard FH (1995) Selection for rapid growth increases the number and the size of muscle fibres without changing their typing in chickens Journal of Muscle Research and Cell Motility 16 95-102 
Reshef R, Maroto M and Lassar AB (1998) Regulation of dorsal somitic cell fates BMPs and Noggin control the timing and pattern of myogenic regulator expression Genes and Development 12 290-303

Robinson DW and Bradford GE (1969) Cellular response to selection for rapid growth in mice Growth 33 221-229

Ross SA, McCaffery PJ, Drager UC and De Luca LM (2000) Retinoids in embryonal development Physiological Reviews 80 1021-1054

Rowe RWD and Goldspink G 1969 The growth of five different muscles in both sexes of mice I. Normal mice Journal of Anatomy 104 519-530

Roy SH, DeLuca CJ, Snyder-Mackler L, Emley MS, Crenshaw RL and Lyons JP (1990) Fatigue, recovery and low back pain in varsity rowers Medicine and Science in Sports and Excercise 22 463-469

Saltin B (1973) Metabolic fundamentals in exercise Medicine and Science in Sport 5 137-146

Semsarian C, Wu MJ, Ju YK, Marciniec T, Yeoh T, Allen DG, Harvey RP and Graham RM (1999) Skeletal muscle hypertrophy is mediated by a $\mathrm{Ca}^{2+}$ dependent calcineurin signalling pathway Nature 400 576-581

Simoneau J-A and Bouchard C (1995) Genetic determinism of fiber type proportion in human skeletal muscle FASEB Journal 9 1091-1095

Skapek SX, Rhee J, Spicer DB and Lassa AB (1995) Inhibition of myogenic differentiation in proliferating myoblasts by cyclin D1-dependent kinase Science 267 1022-1024

Snow DH 1983 Skeletal muscle adaptations: a review. In Exercise Physiology pp 160-164 Ed. DH Snow, SGB Persson and RJ Rose. Granta Editions, Cambridge

Spence MS, Yip J and Erickson CA (1996) The dorsal neural tube organize the dermamyotome and induces axial myocytes in the avian embryo Development 122 231-241

Stern HM, Brown AMC and Hauschka SD (1995) Myogenesis in paraxia mesoderm preferential induction by dorsal neural tube and by cells expressing Wnt-1 Development 121 3675-3686

Stickland NC and HandelSE (1986) The numbers and types of muscle fibres in large and small breeds of pigs Journal of Anatomy 147 181-189

Stockdale FE (1992) Myogenic cell lineages Developmental Biology 154 284-298

Tajbakhsh S, Borello U, Vivarelli E, Kelly R, Papkoff J, Duprez D, Buckingham M and Cossu G (1998) Differential activation of Myf5 and MyoD by different Wnts in explants of mouse paraxial mesoderm and the later activation of myogenesis in the absence of Myf5 Development 125 4155-4162

Thibault MC, Simoneau JA, Cote C, Boulay MR, Lagasse P, Marcotte M and Bouchard C (1986) Inheritance of human muscle enzyme adaptation to isokinetic strength training Human Heredity 36 341-347

Thompson CH, Sanderson AL, Sandeman D, Stein C, Borthwick A, Radda GK and Phillips DIW (1997) Fetal growth and insulin resistance in adult life: role of skeletal muscle morphology Clinical Science 92 291-296

Torok MA, Gardiner DM, Izpisua-Belmonte JC and Bryant SV (1999) Sonic hedgehog (Shh) expression in developing and regenerating axolotl limbs Journal of Experimental Zoology 284 197-206

Valdez MR, Richardson JA, Klein and Olson EN (2000) Failure of Myf5 to support myogenic differentiation without myogenin, MyoD and MRF4 Developmental Biology 219 287-298
Valin C, Touraille C, Vigneron P and Ashmore C R 1982 Predicition of lamb meat quality traits based on muscle biopsy fibre typing Meat Science 6 257-263

Vestergaard M, Therkildsen M, Henckel P, Jensen, LR Andersen HR and Sejrsen K (2000) Influence of feeding intensity, grazing and finishing feeding on meat and eating quality of young bulls and the relationship between muscle fibre characteristics, fibre fragmentation and meat tenderness Meat Science 54 187-195

Wade AJ, Marbut MM and Round JM (1990) Muscle fibre type and aetiology of obesity Lancet 335 805-808

Walker DW and Luff AR (1995) Functional development of fetal limb muscles a review of the roles of activity, nerves and hormones Reproduction Fertility Development 7 391-398

Walsh K and Perlman H (1997) Cell cycle exit upon myogenic differentiation Current Opinion in Genetics and Development 7 597-602

Wang J, Guo K, Wills KN and Walsh K (1997) Rb functions to inhibit apoptosis during myocyte differentiation Cancer Research 57 351-354

Ward SS and Stickland NC (1991) Why are slow and fast muscles differentially affected during prenatal undernutrition? Muscle and Nerve 14 259-267

Westerblad H and Allen DG (1991) Changes in myoplasmic calcium concentration during fatigue in single muscle fibers Journal of General Physiology 98 615-635

White P and Dauncey MJ (1999) Differential expression of thyroid hormone receptor isoforms is strikingly related to cardiac and skeletal muscle phenotype during postnatal development Journal of Molecular Endocrinology $23241-54$

Wigmore PM and Dunglison GF (1998) The generation of fiber diversity during myogenesis International Journal of Developmental Biology 42 117-125

Wigmore PM and Stickland NC (1983) Muscle development in large and small pig fetuses Journal of Anatomy 137 235-245

Wigmore PM, Maleki F, Evans DJR and McErlain M (1996) After embryonic day 17 , distribution of cells on surface of primary muscle fibres in mouse is non-random Developmental Dynamics 207 215-221

Williams BA and Ordahl CP (1994) Pax-3 expression in segmental mesoderm marks early stages in myogenic cell specification Development 120 785-796

Wilson SJ, Ross JJ and Harris AJ (1988) A critical period for formation of secondary myotubes defined by prenatal undernourishment in rats Development 102 815-21

Wilson SJ, McEwan JC, Sheard PW and Harris AJ (1992) Early stages of myogenesis in a large mammal formation of successive generations of myotubes in sheep tibialis cranialis muscle Journal of Muscle Research and Cell Motility 13 534-550

Zamora F, Debiton E, Lepetit J, Dransfield E and Ouali A (1996) Predicitng variability of ageing and toughness in beef $M$. longissimus lumborum et thoracis. Meat Science 43 321-333

Zhang M and McLennan IS (1995) During secondary myotube formation, primary myotubes preferentially absorb new nuclei at their ends Developmental Dynamics 204 168-177 